\title{
Differential Effects of Statins and Alendronate on Cholinesterases in Serum and Brain of Rats
}

\author{
L`. CIBIČKOVÁ $^{1}$, V. PALIČKA ${ }^{2}$, N. CIBIČEK ${ }^{2}$, E. ČERMÁKOVÁ ${ }^{3}$, S. MIČUDA $^{4}$, \\ L. BARTOŠOVÁ ${ }^{5}$ D. JUN ${ }^{5}$
}

${ }^{1}$ Second Department of Internal Medicine, ${ }^{2}$ Institute of Clinical Biochemistry and Diagnostics, ${ }^{3}$ Department of Biophysics and Biostatistics, ${ }^{4}$ Department of Pharmacology, Charles University in Prague, Medical Faculty in Hradec Králové and University Hospital Hradec Králové and ${ }^{5}$ Department of Toxicology, University of Defense, Faculty of Military Health Sciences, Hradec Králové, Czech Republic

Received September 20, 2006

Accepted October 27, 2006

On-line available November 6, 2006

\begin{abstract}
Summary
Acetylcholinesterase (AChE) inhibitors represent standard treatment of Alzheimer's disease. Cholesterol plays an important role in Alzheimer's disease development. Because cholesterol synthesis may be inhibited by statins or bisphosphonates, we hypothesized that these drugs might possibly have an influence on cholinesterases. Moreover, we also evaluated if the cholesterol-lowering agents that cross the blood-brain barrier (e.g. simvastatin) should be more effective than those which do not (e.g. atorvastatin). Four groups of rats were orally administered simvastatin, atorvastatin, alendronate or vehicle for seven days. Thereafter, blood samples were taken and the basal ganglia, septum, frontal cortex, and hippocampus were isolated from brains for measurement of acetylcholinesterase activity. In the blood, activities of neither acetyl- nor butyrylcholinesterase were influenced by any of the applied drugs. In the brain, no significant changes in AChE activity were observed after administration of atorvastatin. Both simvastatin and alendronate significantly suppressed the activity of AChE in the frontal cortex. In conclusion, our results confirmed the hypothesis that cholesterol-modifying drugs modulate $\mathrm{AChE}$ activity and it is more reasonable to use a blood-brain barrier penetrating drug.
\end{abstract}

Key words

Simvastatin $\bullet$ Atorvastatin $\bullet$ Alendronate $\bullet$ Cholesterol $\bullet$ Acetylcholinesterase $\bullet$ Alzheimer's disease

\section{Introduction}

Alzheimer's disease (AD) is a neurodegenerative disorder characterized by progressive memory deficits, cognitive impairment and personality changes. The pathogenic event that characterizes $\mathrm{AD}$ is an abnormal brain accumulation of amyloid $\beta$-peptide $(A \beta)$. One of the major causes of consequent memory derangement lies in a deficiency in cholinergic neurotransmission. Current therapeutic strategies for $\mathrm{AD}$ focus on cognitive deficit alleviation solely via direct AChE inhibition (Grutzendler and Morris 2001). Even though traditional medications 
like donepezil, rivastigmin or galantamin are at present a "golden standard" in treatment of AD, they are indicated as symptomatic drugs, may be less tolerable and represent a considerable financial burden. The question arises, whether the present evidence points to any alternative/additional therapeutic approach that might enhance the tolerability and reduce the costs associated with the treatment of AD.

As alternative therapeutic approach to reduce symptoms of $\mathrm{AD}$ and to slow progression of the disease, several different classes of agents have been suggested, including $A \beta$ vaccination, metal chelators, antiinflammatory drugs or cholesterol-lowering drugs. Among these drugs, cholesterol-modifying agents offer a safe and readily available alternative. The reason is that cholesterol has been shown to be involved in the pathophysiology of AD. Higher serum levels of cholesterol raise $A \beta$ (Sparks 1996), facilitate the deposition of $A \beta$ into plaques that are important for the development of AD. Cholesterol inhibits alpha-secretase and hence hinders production of neuroprotective solubile APPs (Bergmann 2000). Several but not all (Rea et al. 2005, Zandi et al. 2005) epidemiological reports have indicated, that classical cholesterol-lowering drugs such as statins might provide protection against dementia (Rockwood et al. 2002, Zamrini et al. 2004). Moreover, bisphosphonates (e.g. alendronate) in supratherapeutical doses were also found to be able to lower cholesterol levels in human blood (Canigga et al. 1974).

The aim of the present study was to test the hypothesis that cholesterol-lowering drugs have an influence on the activity of cholinesterases $(\mathrm{ChE})$ in rat brain and blood. For this purpose, we chose classical (statins) and atypical (bisphosphonate) ones. We also suggested that drugs, that cross the blood-brain barrier (e.g. simvastatin, alendronate), should be more effective in this aspect than those which do not exhibit such potency (e.g. atorvastatin).

\section{Methods}

\section{Animals}

Adult male rats of the Wistar strain (240-280 g) were obtained from Biotest, Konárovice, Czech Republic. Animals were housed in animal quarters for at least seven days prior to the experiments under controlled environmental conditions $\left(22-24{ }^{\circ} \mathrm{C}, 40-60 \%\right.$ relative humidity, air exchange 12-14 times per hour, 12-h lightdark cycle periods). The rats had free access to standard laboratory rat chow pellets (ST 1-TOP, Velaz, Prague,
Czech Republic) except for 16-18 h before and $0.5 \mathrm{~h}$ after the experiment. Tap water was provided ad libitum. Drugs were administered by gavage every day between 9:00 and 11:00 $\mathrm{h}$ for seven days. All animals received care in accordance with the guidelines set by the institutional Animal Use and Care Committee of Charles University in Prague, Czech Republic. All experimental procedures were approved by the Committee for Protection of Animals against Cruelty (Charles University in Prague, Faculty of Medicine in Hradec Králové, Czech Republic).

\section{Experimental protocol}

The animals were randomly divided into four groups, eight subjects in each. The first (control) group received vehicle only (water), the second was administered atorvastatin $(0.05 \mathrm{mg} / \mathrm{g}$, Pfizer, Gorecke AG Freiburg, Germany), the third ingested simvastatin (0.05 mg/g, IVAX Pharmaceuticals, Czech Republic) and the fourth was exposed to alendronate $(0.003 \mathrm{mg} / \mathrm{g}$, Merck Sharp \& Dohme B.V., Netherlands). The used dosage was based on the data given in literature. The last day of the experiment, one hour after the last drug administration (respecting their $\mathrm{C}_{\max }$ ), the animals were sacrificed by exsanguination (blood withdrawal) from the abdominal aorta under ether anesthesia. Their brains were immediately removed and stored at $-20^{\circ} \mathrm{C}$ until analysis.

\section{Clinical chemistry}

After removal of the brain, the following regions were isolated: basal ganglia, septum, frontal cortex and hippocampus. Individual parts of the brain were homogenized in distilled water using a homogenizer (Ultra Turrax T18). Erythrocytes were obtained from plasma by centrifugation $(10 \mathrm{~min}$ at $3000 \mathrm{rpm}$ at laboratory temperature). The activities of $\mathrm{AChE}$ and BuChE were determined with a modified method of Ellman et al. (1961). Briefly, to $0.4 \mathrm{ml}$ of 5,5'-dithiobis2-nitrobenzooic acid (DTNB) in $0.2 \mathrm{ml} \mathrm{1,1,1-tris-}$ (hydroxymethyl)aminomethane (TRIS)-HCl buffer ( $\mathrm{pH}$ 7,6) $100 \mu \mathrm{l}$ of red blood cell hemolysate $(50 \mu \mathrm{l}$ erythrocytes and $950 \mu \mathrm{l}$ water) (or $100 \mu \mathrm{l}$ plasma - for measurement of BuChE activity) and $1.3 \mathrm{ml}$ TRIS-HCl buffer were added. The reaction was initiated by addition of $0.2 \mathrm{ml}$ of substrate - acetylthiocholine (for measurement of AChE activity) or butyrylthiocholine (for measurement of BuChE activity). The absorbance was measured at $412 \mathrm{~nm}$ for $5 \mathrm{~min}$ using a spectrophotometer (UVIKON 942). Solutions of different cysteine concentrations (added instead of the hemolysate) were 


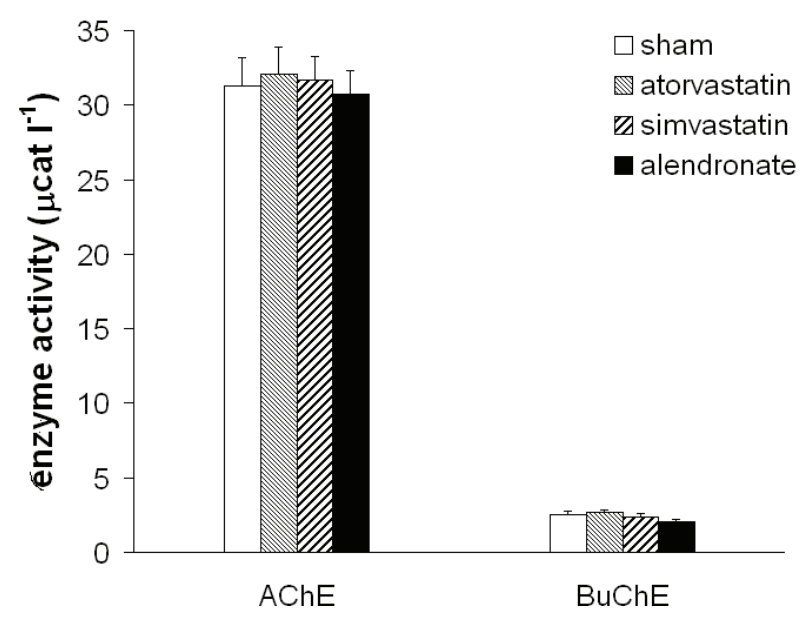

Fig. 1. The effect of atorvastatin, simvastatin and alendronate on AChE activity in erythrocytes and BuChE activity in serum. Data are expressed as means \pm S.E.M.

prepared for calibration. Each measurement was repeated three times. All measurements were conducted under standard laboratory temperature.

\section{Statistical analyses}

Results are expressed as the means \pm S.E.M. for the indicated number of experiments. The data were processed by the programs NCSS 2004 and Statistica. Normality was tested using the Kolmogorov-Smirnov test. For statistical evaluation, analysis of variance with post hoc Fisher's LSD multiple-comparison test (between group comparisons) were applied. The chosen level of significance was $\alpha=0.05$.

\section{Results}

\section{Effect on BuChE and AChE in the blood}

We investigated whether statins or alendronate would directly affect the activity of cholinesterases in blood and serum. One hour after the last application of drugs, trunk blood was collected and the activity of enzymes was measured. Comparison of data from control group with respective values from pretreated animals did not show any significant decrease in activity of either AChE or BuChE (Fig. 1).

\section{Effect on AChE in the brain}

Activity of AChE in the control group was compared with that measured in the atorvastatin, simvastatin and alendronate group. Seven day administration of these agents had no statistically significant effect on the AChE activity in septal, basal

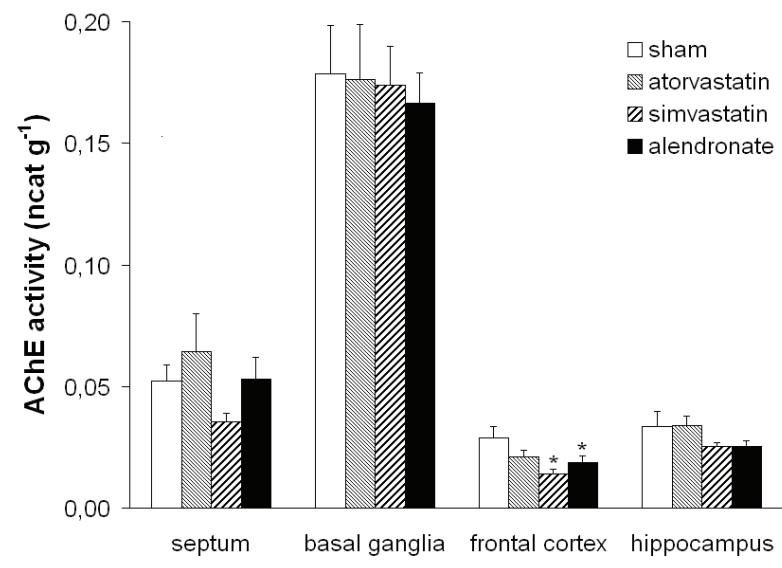

Fig. 2. The effect of atorvastatin, simvastatin and alendronate on AChE activity in brain (septum, basal ganglia, frontal cortex and hippocampus). Data are expressed as means \pm S.E.M. * denotes significant difference $(p<0.05)$ compared to sham group.

ganglia or hippocampal areas of the rat brain (Fig. 2). In contrast, simvastatin and alendronate significantly decreased the AChE activity in the frontal cortex (Fig. 2).

\section{Discussion}

Cholinesterases $(\mathrm{ChE})$ is a generic term used for two related enzymes that hydrolyze choline esters acetylcholinesterase (AChE, EC 3.1.1.7) also known as type $1 \mathrm{ChE}$ and butyrylcholinesterase (BuChE, EC 3.1.1.8) also known as type II ChE (Patočka et al. 2004).

Cholesterol-independent influence of statins on cholinesterase activities

Human plasma BuChE (but not AChE) activity was found to be inhibited by lovastatin and simvastatin in vitro (Darvesh et al. 2004). However, this finding was not confirmed in vivo (Muacevic-Kataneda et al. 2005). In the present in vivo experiment, we measured both cholinesterase activities in rodent plasma. In agreement with the latter work, we observed no significant modification of the enzymatic activities even after application of simvastatin.

\section{Cholesterol-dependent influence of statins on cholinesterase activities}

Cholesterol has been shown to be directly involved in the pathogenesis of AD. Its levels in the brain and in the blood were shown to correlate positively with the amount of $\mathrm{A} \beta$, the characteristic $\mathrm{AD}$ protein which in turn possesses the potency to increase AChE activity with consequent reduction of cholinergic transmission in vitro 
(Kuo et al. 1998, Arvanitakis et al. 2000, Hu et al. 2003). Sparks et al. (2002) hypothesized that it is the excess of cholesterol outside neurons that produces AD-like pathologic changes. Indeed, blockade of cholesterol synthesis by blood-brain barrier (BBB) penetrating statins produced a decrease in $\mathrm{A} \beta$ both in vitro and in vivo (Simons et al. 1998, Fassbender et al. 2001). Our results of decreased AChE activity in the brain of animals pretreated with BBB-penetrating statin (simvastatin) agree with these findings.

An important question has arisen as to the feasibility of using a statin that penetrates through the BBB. Among the six widely prescribed statins, lovastatin, simvastatin and cerivastatin are BBB-penetrating, while atorvastatin, pravastatin and fluvastatin are not. Preferential use of BBB-penetrating statins was challenged by some authors because direct excessive inhibition of cholesterol synthesis within the CNS during statin administration would in turn inhibit normal essential cholesterol synthesis (Sparks et al. 2002). This idea was supported by another study, where cholesterol loss from neuronal membrane enhanced $A \beta$ generation in the hippocampus of humans and transgenic mice (AbadRodriguez et al. 2004). In addition, Petanceska et al. (2002) suggested that it might be another mechanism than lowering of cholesterol, which mediates the effect of statins on $A \beta$. They demonstrated a reduction in brain $A \beta$ accumulation and deposition by atorvastatin (non-BBBpenetrating statin), whereas total brain cholesterol remained unchanged (Pentaceska et al. 2002). This is in accordance with epidemiologic data, which suggest a decreased prevalence of dementia among individuals using statins irrespective of their BBB-permeability (Wolozin et al. 2000). Therefore, to address the question how brain AChE activity is altered by permeation status of statin used, we examined the effects of both - BBB-not crossing drugs (atorvastatin, which should be without influence on cholesterol in the brain) and BBB crossing drugs (simvastatin, which affects cholesterol metabolism in the brain) (Locatelli et al. 2002). Our results have shown that atorvastatin did not decrease the activity of $\mathrm{AChE}$, whereas simvastatin exhibited such potency in the frontal cortex, where the accumulation of $A \beta$ is usually the highest. These results together with data reported by others (Simons et al. 1998, Fassbender et al. 2001) indicate that for reduction of AChE activity in the brain, it is more reasonable to use a statin that penetrates the BBB. Cholesterol and/or A $\beta$-dependency of the observed effect of simvastatin on AChE were not addressed by this study. Further studies are needed to determine the potential negative effect of possible brain cholesterol loss due to statin treatment.

\section{Bisphosphonates}

Previous reports demonstrated lowered cholesterol and total lipid levels in human blood after treatment with supratherapeutic doses of bisphosphonate (etidronate, Canigga et al. 1974). Farnesyl diphosphate synthase, i.e isopentenyl transferase, was identified as the molecular target of bisphosphonates in the cholesterol biosynthesis pathway (Rezka and Rodan 2004). In parallel with statins, we hypothesized that the cholesterollowering potency of these drugs might be beneficial in the reduction of $\mathrm{AChE} / \mathrm{BuChE}$ activities in the blood and/or brain. We are unaware of a study describing the influence of bisphosphonates on cholinesterases. In our trial, alendronate, a BBB-penetrating drug, was applied. The studied drug was not able to decrease significantly serum activity of AChE or BuChE. Like simvastatin, however, alendronate significantly decreased the activity of AChE in the frontal cortex, a change not seen in other parts of the brain. Further experiments are needed to account for the precise role that bisphosphonates play in the cholinergic system. We also suggest that human data should be available to elucidate a possible modifying effect of these cholesterol-lowering drugs on dementia.

\section{Conclusions}

To our best knowledge, the present study is the first to show an influence of BBB-crossing cholesterollowering drugs (simvastatin and alendronate) on $\mathrm{AChE}$ activity in the brain. If the findings of this pilot study will be supported by other studies, they might have significant clinical implications as the levels of cholesterol, $A \beta$ and acetylcholine (all possibly modulated by the studied drugs) play important roles in the pathogenesis of Alzheimer's disease.

\section{Acknowledgements}

This study was supported principally by Research Project MZO 00179906 and by an internal grant of Medical Faculty in Hradec Králové, Charles University in Prague.

\section{Abbreviations}

AD - Alzheimer's disease; APP - amyloid precursor protein, $\mathrm{A} \beta$ - amyloid $\beta$-peptide; $\mathrm{ChE}$ - cholinesterase; AChE - acetylcholinesterase; BBB - blood-brain barrier; BuChE - butyrylcholinesterase; N-BPs - nitrogencontaining bisphosphonates 


\section{References}

ABAD-RODRIGUEZ J, LEDESMA MD, CRAESSAERTS K, PERGA S, MEDINA M, DELACOURTE A, DIGWALL C, DE STROOPER B, DOTTI CG: Neuronal membrane cholesterol loss enhances amyloid peptide generation. J Cell Biol 167: 953-960, 2004.

ARVANITAKIS Z, LUCAS JA, GRAFF-RADFORD NR: Correlation between serum cholesterol parameters and plasma amyloid beta protein. Neurobiol Aging 21: 96, 2000.

BERGMANN CH: Diversification of gamma-secretase activity versus beta-secretase inhibition by cholesterol depletion. Neurobiol Aging 21: 278, 2000.

CANIGGA A, GENNARI C, PICCI M: Bisphosphonate lowers cholesterol and total lipid levels in the blood of humans. Boll Soc Ital Biol Sper 50: 1416-1422, 1974.

DARVESH S, MARTIN E, WALSH R, ROCKWOOD K: Differential effects of lipid-lowering agents on human cholinesterases. Clin Biochem 37: 42-49, 2004.

ELLMAN GL, COURTNEY KD, ANDRES VL, FEATHERSTONE RM: A new and rapid colorimetric determination of acetylcholinesterase activity. Biochem Pharmacol 7: 88-95, 1961.

FASSBENDER K, SIMONS M, BERGMANN C, STROICK M, LUTJOHANN D, KELLER P, RUNZ H, KUHL S, BERTSCH T, VON BERGMANN K, HENNERICI M, BEYREUTHER K, HARTMANN T: Simvastatin strongly reduces levels of Alzheimers disease $\beta$-amyloid peptides A $\beta 42$ and $\mathrm{A} \beta 40$ in vitro and in vivo. Proc Natl Acad Sci USA 98: 5856-5861, 2001.

HU W, GRAY NW, BRIMIJOIN S: Amyloid-beta increases acetylcholinesterase expression in neuroblastoma cells by reducing enzyme degradation. $J$ Neurochem 86: 470-478, 2003.

GRUTZENDLER J, MORRIS JC: Cholinesterase inhibitors for Alzheimer's Disease. Drugs 61: 41-52, 2001.

KUO YM, EMMERLING MR, BISGAIER CL, ESSENBURG AD, LAMPERT HC, DRUMM D, ROHER AE: Elevated low-density lipoprotein in Alzheimer's disease correlates with brain A-beta 1-42 levels. Biochem Biophys Res Commun 252: 711-715, 1998.

LOCATELLI S, LUTJOHANN D, SCHMIDT HH, OTTO C, BEISIEGEL U, VON BERGMANN K: Reduction of plasma 24-hydroxycholesterol (cerebrosterol) levels using high-dosage simvastatin in patients with hypercholesterolemia: evidence that simvastatin affects cholesterol metabolism in the human brain. Arch Neurol 59: 213-216, 2002.

MUACEVIC-KATANEDA D, BRADAMANTE V, REINEC Z, SUCIC Z, POLJICAIN T, BUSLJETA I, METELKO Z: Clinical study on the effect of simvastatin on butyrylcholinesterase activity. Arzneimittelforschung 55: 271275, 2005.

PATOČKA J, KUČA K, JUN D: Acetylcholinesterase and butyrylcholinesterase - important enzymes of human body. Acta Medica (Hradec Králové) 47: 215-228, 2004.

PETANCESKA SS, DEROSA S, OLM V, DIAZ N, SHARMA A, THOMAS-BRYANT T: Statin therapy for Alzheimer's disease. Will it work? J Mol Sci 16: 155-161, 2002.

REA TD, BRITNER JC, PSATY BM, FITZPATRICK AL, LOPEZ OL, NEWMAN AB, HAZZARD WR, ZANDI PP, BURKE GL, LYKETSOS CG, BERNICK C, KULLER LH: Statin use and the risk of incident dementia: the cardiovascular health study. Arch Neurol 62: 1047-1051, 2005.

REZKA AA, RODAN GA: Nitrogen-containing bisphosphonate mechanism of action. Mini Rev Med Chem 4: 711-719, 2004.

ROCKWOOD K, KIRKLAND S, HOGAN DB, MACKNIGHT C, MERRY H, VERREAULT R, WOLFSON C, MCDOWELL I: Use of lipid-lowering agents, indication bias, and the risk of dementia in community-dwelling elderly people. Arch Neurol 59: 223-227, 2002.

SIMONS S, KELlER P, DE STROOPER B, BEYREUTHER K, DOTTI CG, SIMONS K: Cholesterol depletion inhibits the generation of beta-amyloid in hippocampal neurons. Proc Natl Acad Sci USA 95: 6460-6464, 1998.

SPARKS DL: Intraneuronal $\beta$-amyloid immunoreactivity in the CNS. Neurobiol Aging 17: 291-299, 1996.

SPARKS DL, CONNOR DJ, BROWNE PJ, LOPEZ JE, SABBAGH MN: HMG-CoA reductase inhibitors (statins) in the treatment of Alzheimer's disease and why it would be ill-advise to use one that crosses the blood-brain barrier. J Nutr Health Aging 6: 324-331, 2002. 
WOLOZIN B, KELLMAN W, RUOSSEAU, CELESIA G, SIEGEL G: Decreased prevalence of Alzheimer disease associated with 3-hydroxy-3-methylglutaryl coenzyme A reductase inhibitors. Arch Neurol 57: 1439-1443, 2000.

ZAMRINI E, MCGWIN G, ROSEMAN JM: Association between statin use and Alzheimer's disease. Neuroepidemiology 23: 94-98, 2004.

ZANDI PP, SPARKS DL, KHACHATURIAN AS, TSCHANZ J, NORTON M, STEINBERG M, WELSH-BOHMER KA, BREITNER JC: Do statins reduce risk of incident dementia and Alzheimer disease? The Cache cohort study. Arch Gen Psychiatry 62: 217-224, 2005.

\section{Corresponding author}

L`. Cibičková, Second Department of Medicine, University Hospital (FN), Sokolská 581, 50005 Hradec Králové, Czech Republic. Fax: +420-495-514022. E-mail: cibickoval@lfhk.cuni.cz, cibickova@seznam.cz 